\title{
PAPO CABEÇA: UMA OPORTUNIDADE, NO ENSINO SUPERIOR, DE REFLETIR SOBRE A VIDA
}

\author{
FOOD FOR THOUGHT: AN OPPORTUNITY, IN GRADUATE LEVEL, TO REFLECT \\ ABOUT LIFE
}

Márcia Regina Pires ${ }^{1}$

\begin{abstract}
RESUMO
Este ensaio constitui-se no relato de um projeto realizado em uma universidade particular, como uma das ações de um programa de atendimento ao estudante. O projeto constituiu-se de uma série de palestras, intituladas Papo Cabeça, que teve como objetivo possibilitar ao aluno pensar sobre si mesmo, sobre o outro, sobre a sociedade, sobre a vida, especialmente sobre o momento que está vivendo no universo acadêmico e suas ações pessoais e profissionais. Assuntos como, por exemplo, juventude, conhecimento, fraternidade, honestidade foram tematizados por meio de abordagens mais leves, num clima informal, sem a pressão de aprender para ser avaliado. A forma de abordar os temas e a articulação feita entre eles trouxeram a possibilidade dos alunos perceberem o que muitas vezes está naturalizado no dia a dia. Os discentes analisaram fatos do cotidiano, ações, valores, identificando as variáveis envolvidas, as relações entre elas, principalmente, abordando a relação de causa e consequência. Isso oportunizou que refletissem sobre seus próprios valores, seus ideais, suas condutas e suas perspectivas. Constatamos que a universidade deve, cada vez mais, proporcionar momentos de discussão em que os alunos sejam convidados a participar, a refletir e dialogar acerca de problemas da contemporaneidade, com a mediação qualificada de educadores.
\end{abstract}

PALAVRAS-CHAVE: Universidade. Atitude. Vida.

\begin{abstract}
This essay comprises a report of a project carried out in a private university, as one of the actions part of a program of student support. The project comprises a serie of lectures, named Food for Thought, which has the objective to enable the students to think about themselves, about other individuals, about life, specially about the moment they are living within academia and their personal and professional actions. Topics such as youth, knowledge, fraternity, honesty were addressed by way of a lighter approach, in an informal environment, without the pressure of learning in order to be tested. The approach and articulation of subjects among the students enabled them to perceive what is naturalized in their everyday life. The professors analyzed facts of day-to-day life, attitudes, values, identifying the possible variables, the relationship between them, mainly addressing the relation between cause and effect. This allowed the students to reflect about their own values, their goals, their conducts and perspectives. We observed that universities should increasingly provide opportunities for discussion in which the students are invited to participate, reflect and dialogue about modern issues, through the qualified facilitation of professors.
\end{abstract}

KEYWORDS: University. Attitudes. Life.

\section{INTRODUÇÃO: CONTEXTO E PLANEJAMENTO}

O presente ensaio constitui-se no relato de uma experiência de ensino realizada em uma universidade particular, como uma das ações de um programa de atendimento ao estudante. Esse programa tem como objetivo geral oferecer acolhida, amparo,

\footnotetext{
${ }^{1}$ Universidade Federal do Triângulo Mineiro - UFTM. Email: marciapires20111@hotmail.com
} 
acompanhamento e estimular a convivência universitária, atendendo o estudante em suas necessidades, interesses e desejos.

Nessa perspectiva, oferece subprogramas que possibilitam aos alunos participarem efetivamente de atividades culturais, recreativas, esportivas e ainda ter atendimento psicológico, social, entre outros, traduzindo-se numa forma de acolher, de fomentar as interações na comunidade acadêmica e de ser um ponto de apoio ao estudante. Entre as ações desenvolvidas, o programa oferece semanalmente aos alunos palestras de diferentes temáticas, realizadas por pessoas de várias áreas do saber e papéis sociais, como tenentes, médicos, escritores etc. Há, também, palestras ministradas pelos professores da própria instituição. Todas elas valem créditos para o componente Atividades Complementares que é comum a todas as graduações. Assim, a universidade tenta superar a problemática do predomínio dos conteúdos técnico-científicos em detrimento de outros também importantes na formação humana do educando; possibilita, ainda, a interdisciplinaridade e a aproximação entre a academia e a comunidade.

Para Pimenta e Anastasiou (2002, p.97), a tarefa da educação é "garantir que [os educandos] se apropriem do instrumental científico, técnico, tecnológico, de pensamento, político, social e econômico, de desenvolvimento cultural, para que sejam capazes de pensar e gestar soluções.“ Sendo assim, é papel da universidade nortear a formação do aluno, no sentido, de ajudá-lo a articular os conhecimentos técnico-científicos aos conhecimentos de ordem pessoal, contribuindo com que enxergue as situações vividas por ele e os fenômenos sociais com maior clareza.

Para Libâneo (2001, p.7)

A educação é uma prática social que busca realizar nos sujeitos humanos as características de humanização plena. Todavia, toda educação se dá em meio a relações sociais. Numa sociedade em que essas relações se dão entre grupos sociais antagônicos, com diferentes interesses, em relações de exploração de uns sobre outros, a educação só pode ser crítica, pois a humanização plena implica a transformação dessas relações.

A universidade, com essa perspectiva de educação, oportuniza aos discentes desenvolver sua criticidade, sua capacidade de levantar hipóteses, de identificar soluções, de refletir acerca do contexto imediato e mais amplo para depois agir.

Nesse sentido, considerando a importância da educação abordar as várias dimensões dos seres humanos, a experiência pedagógica, tema deste ensaio vai ao encontro do que os autores defendem. Tal experiência constituiu-se de um projeto formado por uma série de http://www.uftm.edu.br/revistaeletronica 
palestras, intitulada Papo Cabeça, que teve como objetivo possibilitar ao aluno pensar sobre si mesmo, sobre o outro, sobre a sociedade, sobre a vida, especialmente sobre o momento que está vivendo no universo acadêmico e suas ações pessoais e profissionais.

Segundo Pimenta e Anastasiou (2002, p.97)

A educação é um processo de humanização. Ou seja, é processo pelo qual se possibilita que os seres humanos se insiram na sociedade humana, historicamente construída e em construção. Sociedade que é rica em avanços civilizatórios e, em decorrência, apresenta imensos problemas de desigualdade social, econômica e cultural. De valores. De finalidades.

A partir da necessidade de contribuir com o processo de humanização do aprendiz, no projeto Papo cabeça, tivemos a pretensão de oportunizar momentos em que o aluno refletisse sobre temas e situações-problemas vivenciados em sua vida e na sociedade contemporânea, e, assim, conjecturar possíveis soluções, pensando seu papel enquanto futuro profissional nesse contexto. Nessa perspectiva, buscamos mediar reflexões acerca de temáticas cotidianas e transversais à existência do educando, trazendo temas como a relação pais e filhos; a relação do profissional com seu conhecimento e com a sociedade; as relações interpessoais; a juventude e a senilidade; o desenvolvimento das inteligências emocional e intelectual; a construção de valores humanos; a ética e a moral, a desigualdade social, o planejamento da vida, entre outros.

Queríamos também, como o próprio nome do projeto sugere, que os encontros fossem leves, agradáveis, atrativos ao aluno, e que se constituíssem, de fato, como um convite a uma conversa informal, mas significativa. Assim, apesar de cada encontro se constituir metodologicamente como palestra, houve momentos em que os alunos foram convidados a falar, expondo seus pontos de vista.

\section{A experiência de fato}

O primeiro aspecto que nos chamou a atenção foi a quantidade de alunos que assistiram as palestras, muitas vezes, lotando noventa vagas. Como as palestras eram abertas a toda comunidade acadêmica, tivemos alunos de diversos cursos.

Sempre, num primeiro momento, o coordenador do programa de atendimento ao estudante dialogava com os alunos, dando alguns recados, dizendo sobre a importância da palestra e apresentando a ministrante. Nesse momento, o coordenador brincava com os 
estudantes, chamando alguns pelo nome e respondendo dúvidas. É importante ressaltar que a relação de cordialidade e de amizade estabelecida entre o coordenador e os alunos, já de início, gerava um clima agradável, tranquilo e mais informal, ou seja, propício ao diálogo.

A palestra era iniciada a partir de imagens ou de situações-problemas ou de questionamentos, sempre com a preocupação de instigar o aluno a refletir, a realizar perguntas e a participar, fazendo-o articular o conteúdo com sua vivência. Para fomentar as discussões, eram utilizadas charges, fragmentos de reportagens, letras de músicas, pequenos vídeos, ou seja, textos e assuntos do cotidiano. Em alguns momentos, eram aplicadas dinâmicas, com o objetivo de oportunizar que os alunos pudessem falar acerca da compreensão que eles tinham em relação ao tema, mas de uma forma lúdica, mesclando brincadeiras e discussões.

Os alunos prestavam bastante atenção, isso era claramente percebido, porque não havia praticamente nenhuma conversa paralela entre eles e, também, não se distraíam mexendo no celular - os rostos estavam sempre atentos à palestrante. Entretanto, mesmo com essa atenção e com uma metodologia que estimulasse a interação e o diálogo com os alunos, a participação deles com perguntas, com respostas, com intervenções espontâneas era bastante restrita. Embora demonstrassem interesse, os alunos pouco se expressavam oralmente a respeito das temáticas. Isso foi algo que nos chamou a atenção.

No final de cada palestra, convidávamos alguns alunos para que dessem o depoimento sobre o que tinham achado sobre o encontro e todos os depoimentos foram positivos. As palestras foram realizadas a cada dois meses, durante um semestre, durando 50 min cada uma.

\section{CONSIDERAÇÕES FINAIS}

A experiência nos deixou uma única certeza, mas vários questionamentos. A certeza é de que os alunos do ensino superior sentem necessidade de refletir acerca das temáticas sobre as quais abordamos, pois a atenção com que a maioria assistiu à palestra é algo contundente. Entretanto, a tímida participação dos discentes em relação às discussões nos faz levantar algumas hipóteses: os alunos têm vergonha de se expressar em ambientes que há alunos de variados cursos e conhecimentos? Têm vergonha de se expor? Não dominam a habilidade de oratória? Não acreditam que o conhecimento que possuem é relevante? Não foram formados para dar opinião? 
Sabemos que as situações vivenciadas na educação são complexas, porque muitas são as variáveis que podem influenciá-las, por isso, não conseguiríamos levantar, neste texto, todas as hipóteses que envolvem essa circunstância e esse não é nosso objetivo.

Por meio dessa experiência, enquanto professores do ensino superior, compreendemos que não podemos negligenciar a dimensão emocional do aprendiz. Sabemos que muitos desses alunos estão, pela primeira vez, distantes de suas famílias e enfrentando circunstâncias totalmente novas. Os desafios do ensino superior os obrigam a desenvolver sua autonomia de forma mais acelerada, para dar conta da vida dentro e fora da universidade.

Nesse sentido, percebemos que o Papo cabeça foi uma oportunidade que alunos e ministrante tiveram para dialogar acerca da experiência da vida, em sua diversidade, em sua cotidianidade. Assuntos profundos foram tematizados por meio de uma conversa leve, num clima informal, sem a pressão de aprender para ser avaliado. A forma de abordar os temas e a articulação feita entre eles trouxeram diferentes formas de perceber o que muitas vezes está naturalizado em nosso dia a dia. A reflexão instigada pelos questionamentos que foram respondidos pelos alunos oralmente, ou apenas, pensados, provocou a possibilidade de se deterem diante de fatos, atitudes e valores, identificando as variáveis envolvidas, e principalmente, abordando a relação de causa e consequência.

A sensação que temos é que os alunos necessitam de mais experiências assim. Eles sentem a necessidade da mediação de pessoas que os ajudem a refletir melhor sobre a dinâmica da vida, que tragam depoimentos, que tragam uma forma nova de olhar para as coisas, para os fatos, para as relações.

Ratificamos que a universidade deve, cada vez mais, preocupar-se com a formação humana do graduando, uma vez que sua necessidade nesse sentido é grande. Entendemos, ainda, que as oportunidades de dialogar acerca dessas questões não podem ser esparsas, mas contínuas. A universidade deve sempre proporcionar momentos de discussão em que os alunos sejam convidados a participar, a emitir sua opinião acerca de problemas da contemporaneidade, refletindo sobre eles com a mediação qualificada de educadores.

\section{REFERÊNCIAS}

DALBERIO, Osvaldo. Ética, Moral e Valores do professor e do aluno. 2011. Disponível em: $<$ http://www.uftm.edu.br/revistaeletronica/index.php/revistatriangulo/article/view/228/pdf >. Acesso em 27 ago. 2015. 
LIBÂNEO, José Carlos. Pedagogia e pedagogos: inquietações e buscas. Disponível em:< http://www.educaremrevista.ufpr.br/arquivos_17/libaneo.pdf>. Acesso em: 27 ago. 2015.

PIMENTA, Selma Garrido, ANASTASIOU, Léa das Graças Camargos. Docência no ensino superior. São Paulo: Cortez, 2002.

RECEBIDO EM: 10/03/2016

APROVADO PARA PUBLICAÇÃO EM: 29/11/2016 